\title{
Analisis Terjadinya Arus Netral Pada Trafo Distribusi 160 kVA
}

\author{
Arfita Yuana Dewi ${ }^{1)}$, Asnal Effendi ${ }^{2)}$, Fahody M. Syafar ${ }^{3)}$ \\ ${ }^{123}$ Institut Teknologi Padang \\ Correspondence email: arfita@itp.ac.id
}

\begin{abstract}
Abstrak: Penyaluran daya pada sistem 3 fasa, tidak terlepas dengan mengalirnya arus di netral trafo, yang akan menimbulkan rugi - rugi daya (losses) dimana arus mengalir ke penghantar netral dan losses yang mengalir ke tanah. Penelitian ini dilakukan untuk mengetahui besar losses yang terjadi akibat terjadinya arus netral yang mengalir di penghantar netral pada trafo distribusi 160kVA. Lokasi penelitian yang diambil adalah pada Trafo Distribusi (G187 T) yang berlokasi di Jl. Hos Cokroaminoto Wisma Ombilin dimana sering terjadi ketidakseimbagan beban. Dari hasil perhitungan dapat diketahui jika kawat netral dengan ukuran penampang $50 \mathrm{~mm}^{2}$ maka arus yang melewati kawat netral dengan persentasi $6,4 \%$ untuk siang hari dan untuk ukuran penampang kawat $70 \mathrm{~mm}^{2}$ maka dapat mengurangi daya yang mengalir ke netral dengan persentase sebesar $4,77 \%$ pembebanan siang. Nilai Efisiensi yang terjadi lebih besar pada pembebanan malam yaitu 94,87\% sedangkan untuk siang hari sebesar 93,44\%. Untuk penyaluran tiap - tiap fasa terutama fasa $\mathrm{S}$ agar dapat diseimbangkan karena daya yang di salurkan pada fasa $\mathrm{S}$ terlalu kecil. Sebaiknya untuk arus kawat netral harus di salurkan ke tanah agar arus yang mengalir di kawat netral menjadi nol.
\end{abstract}

Kata kunci: Arus Netral, Rugi-rugi Daya, Efisiensi.

\begin{abstract}
The Power distribution in a 3-phase system, cannot be separated from the flow of current in the neutral of the transformer, which will cause power losses (losses) where current flows into the neutral conductor and losses that flow into the neutral conductor. This study was conducted to determine the causes and magnitude of power losses that occur due to the occurrence of neutral current flowing in the neutral conductor in a 160kVA distribution transformer. The research location taken is the Distribution Transformer (G187 T) which is located on Jl. Hos Cokroaminoto Wisma Ombilin where load imbalances often occur. From the results, it can be seen that if the neutral wire has a cross-sectional size of 50 mm2, the current that passes through the neutral wire is $6.4 \%$ for the day and for the cross-sectional size of the wire is $70 \mathrm{~mm} 2$, it can reduce the power flowing to the neutral by a percentage of $4.77 \%$. for the daytime. Efficiency value that occurs is greater at night that is $94.87 \%$ while for the day it is $93.44 \%$. For the distribution of each-each phase, especially the S phase, so that it can be balanced because the power supplied to the $S$ phase is too small. We recommend that the current flowing in the neutral wire must be channeled to the ground so that the current flowing in the neutral wire becomes zero.
\end{abstract}

Keywords: Neutral Current, power losses, efficiency.

\section{PENDAHULUAN}

Kebutuhan terhadap energi listrik seiring dengan pertumbuhan ekonomi masyarakat. Maka sangatlah penting untuk menjaga kualitas penyaluran daya listrik. Beberapa faktor yang dapat mempengaruhi hal tersebut harus menjadi perhatian khusus.

Berdampak pada penyediaan tenaga listrik 3 fasa, dengan netral di trafo dapat menyebabkan mengalirnya arus di netral trafo, yang akan menyebabkan terjadinya rugi - rugi daya dimana arus menyalir ke penghantar netral dan Losses yang mengalir ke tanah[6]. Untuk mengoptimalkan penyaluran daya listrik agar tidak terjadinya pengurangan daya yang tersalur, maka peneliti mengadakan penelitian tentang analisis terjadinya arus netral pada transformator distribusi yang terjadi di Jl. Cokrominoto Wisma Ombilin Padang.

\section{TINJAUAN PUSTAKA}

\subsection{Sistem 3 Fasa}

Sistem 3 fasa yang seimbang merupakan sistem dengan nilai arus, tegangan, dan sudut fasa yang ratarata sama. Seperti yang ditunjukkan pada gambar 1 berikut [6],

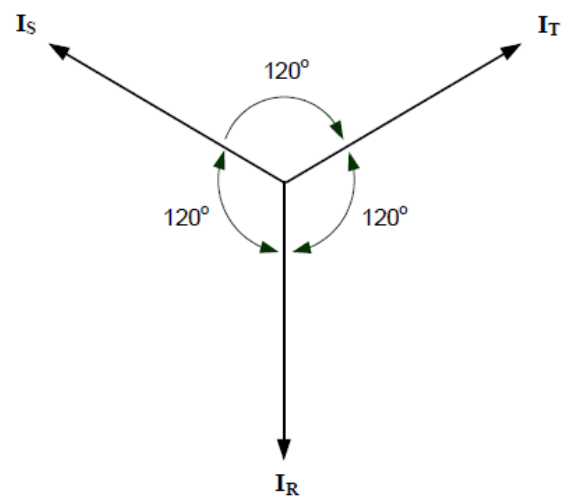

Apabila :

Gambar 1. Vektor Diagram Arus Seimbang

$$
\begin{aligned}
& {[\mathrm{IR}]=\mathrm{a}[\text { I rat }]} \\
& {[\mathrm{IS}]=\mathrm{b}[\text { I rat }]} \\
& [\mathrm{IT}]=\mathrm{c} \text { [ I rat }]
\end{aligned}
$$

Dimana pada keadaan seimbang, nilai $\mathrm{a}=\mathrm{b}=\mathrm{c}=$ 1[6]. Untuk Vektor Diagram Arus tidak seimbang seperti yang ditunjukkan pada gambar 2 berikut, 
Is

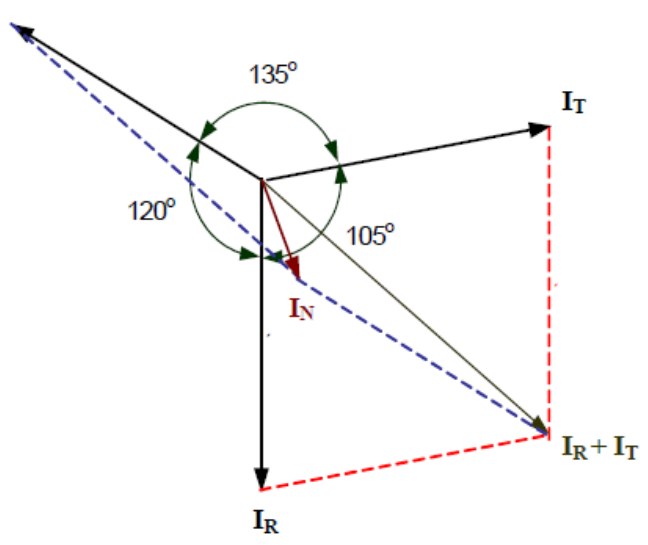

Gambar 2. Vektor Diagram Arus Tidak Seimbang

\subsection{Analisa rugi-rugi daya/losses}

Losses yang terjadi akibat mengalirnya arus netral pada trafo dapat dirumuskan sebagai berikut [1],[4],[5]:

$\mathrm{P}_{\mathrm{N}}=\mathrm{I}_{\mathrm{N}^{2}} \times \mathrm{R}_{\mathrm{N}}$

Dimana:

$\mathrm{P}_{\mathrm{N}} \quad=$ Losses pada penghantar netral trafo (Watt)

$\mathrm{I}_{\mathrm{N}} \quad=$ Arus pada kabel netral trafo (A)

$\mathrm{R}_{\mathrm{N}} \quad=$ Tahanan penghatar netral trafo $(\Omega)$

Sedangkan losses yang diakibatkan karena arus netral yang mengalir ke tanah (ground) dapat dihitung dengan perumusan sebagai berikut:

$$
\mathrm{P}_{\mathrm{G}}=\mathrm{I}_{\mathrm{G}^{2}} \times \mathrm{R}_{\mathrm{G}}
$$

Dimana:

$\mathrm{P}_{\mathrm{G}} \quad=$ Losses akibat arus netral mengalir ke tanah (Watt)

$\mathrm{I}_{\mathrm{G}} \quad=$ Arus pada netral yang mengalir ke tanah (A)

$\mathrm{R}_{\mathrm{G}} \quad=$ Tahanan pembumian pada trafo $(\Omega)$

\subsection{Efisiensi Transformator}

[1]:

Efisiensi transformator, secara matematis ditulis

$$
\eta=\frac{\text { Pout }}{\text { Pin }} \quad \mathrm{x} 100 \%
$$

Pout $=(a+b+c) \cdot$ V.I.Cos $\emptyset$

Pin $=$ Pout + Rugi-rugi

Dimana :

$$
\eta=\text { Efisiensi }
$$

Pout = Daya keluar $($ Watt $)$

Pin = Daya masuk $($ Watt $)$

\section{METODOLOGI}

Jenis penelitian yang dilakukan adalah perhitungan dan analisis terjadinya arus netral pada trafo distribusi, dengan pembebanan siang dan malam hari.

Proses pelaksanaan penelitian ini disajikan seperti pada Gambar 3 berikut :

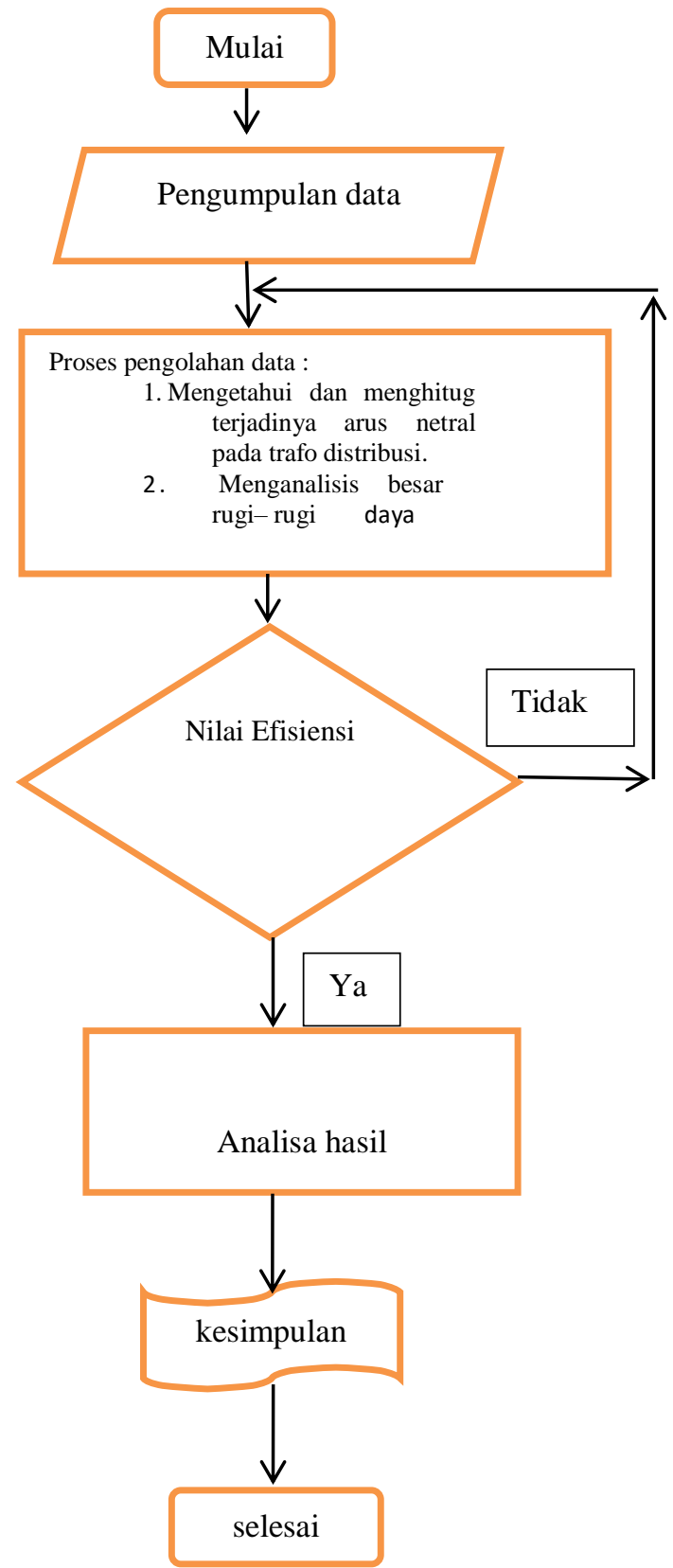

4. HASIL DAN PEMBAHASAN

Tabel 1. Hasil Pengukuran Trafo 160kVA Pembebanan Siang

\begin{tabular}{|c|c|c|c|c|}
\hline Fasa & $\begin{array}{c}\text { S } \\
(\text { KVA })\end{array}$ & $\begin{array}{c}\text { Vp-n } \\
(\mathrm{V})\end{array}$ & $\begin{array}{c}\text { I } \\
(\mathrm{A})\end{array}$ & Cos $\Phi$ \\
\hline \multicolumn{5}{|c|}{ Pengukuran pada siang hari } \\
\hline R & 26,09 & 223 & 117 & 0,8 \\
\hline S & 12,25 & 227 & 54 & 0,8 \\
\hline T & 47,2 & 236 & 200 & 0,8 \\
\hline IN & & $110 \mathrm{~A}$ \\
\hline IG & \multicolumn{5}{|c|}{60,7} \\
\hline RG & \multicolumn{5}{|c|}{4} \\
\hline
\end{tabular}


Tabel 2. Hasil Pengukuran Trafo 160kVA Pembebanan Malam

\begin{tabular}{|c|c|c|c|c|}
\hline Fasa & $\begin{array}{c}\text { S } \\
(\text { KVA })\end{array}$ & $\begin{array}{c}\text { Vp-n } \\
(\mathrm{V})\end{array}$ & $\begin{array}{c}\text { I } \\
(\mathrm{A})\end{array}$ & Cos $\phi$ \\
\hline \multicolumn{5}{|c|}{ Pengukuran pada malam hari } \\
\hline R & 38,64 & 226 & 171 & 0,8 \\
\hline S & 20,38 & 229 & 89 & 0,8 \\
\hline T & 52,66 & 228 & 231 & 0,8 \\
\hline IN & \multicolumn{5}{|c|}{$111 \mathrm{~A}$} \\
\hline IG & 55,6 \\
\hline RG & \multicolumn{5}{|c|}{4} \\
\hline
\end{tabular}

Perhitungan pada penelitian ini menggunakan penghantar netral Trafo berukuran $50 \mathrm{~mm}^{2}$ dengan Resistansi sebesar $0,6842 \Omega / \mathrm{km}$, dan penghantar fasa berpenampang $70 \mathrm{~mm}^{2}$ dengan nilai Resistansi $0,5049 \Omega / \mathrm{km}[3],[4]$.

\subsection{Analisa Pembebanan Trafo}

$\mathrm{S} \quad=160 \mathrm{KVA}=160000 \mathrm{VA}$

$\mathrm{V}=400 \mathrm{~V}$ ( Fasa-fasa )

$I_{F L}=\frac{S}{\sqrt{3} \times V}=\frac{160.000}{\sqrt{3} \times 400}=231,21 \mathrm{~A}$

$I_{\text {rata }- \text { rata siang }}=\frac{\boldsymbol{I R}+\boldsymbol{I S}+\boldsymbol{I T}}{3}=\frac{117+54+200}{3}=123,7 \mathrm{~A}$

$I_{\text {rata }- \text { rata } \text { malam }}=\frac{\boldsymbol{I R}+\boldsymbol{I S}+\boldsymbol{I T}}{3}=\frac{171+89+231}{3}=163,7 \mathrm{~A}$

Persentase pembebanan Trafo pada siang hari :

$\frac{\text { Irata }- \text { rata siang }}{I F L}=\frac{123,7}{231,21} \times 100 \%=53 \%$

Dan pada Malam hari

$\frac{\text { Irata }- \text { rata malam }}{I F L}=\frac{163,7}{231,21} \times 100 \%=70 \%$

\subsection{Analisa Ketidakseimbangan beban trafo}

Analisa nilai arus fasa Trafo menggunakan koefisien a,b dan c pada 2 kondisi pembebanan sebagai berikut :

Siang hari :

$I_{R}=\mathrm{a} \times \mathrm{I}$, maka $\mathrm{a}=\frac{I R}{I}=\frac{117}{123,7}=0,94 \mathrm{~A}$

$I_{S}=\mathrm{a} \times \mathrm{I}$, maka $\mathrm{b}=\frac{I S}{I}=\frac{54}{123,7}=0,43 \mathrm{~A}$

$I_{T}=\mathrm{a} \times \mathrm{I}$, maka $\mathrm{c}=\frac{I T}{I}=\frac{200}{123,7}=1,61 \mathrm{~A}$

Atau dalam persentase berikut :

$\frac{\{|a-1|+|b-1|+|c-1|\}}{3} \times 100 \%=$ $\frac{\{|0,94-1|+|0,43-1|+|1,61-1|\}}{3} \times 100 \%=41 \%$

Malam hari :

$I_{R}=\mathrm{a} \times \mathrm{I}$, maka $\mathrm{a}=\frac{I R}{I}=\frac{171}{163,7}=1,04$

$I_{S}=\mathrm{a} \times \mathrm{I}$, maka $\mathrm{b}=\frac{I S}{I}=\frac{89}{163,7}=0,53$

$I_{T}=\mathrm{a} \times \mathrm{I}$, maka $\mathrm{c}=\frac{I T}{I}=\frac{231}{163,7}=1,41$

Atau dalam persentase berikut :

$\frac{\{|a-1|+|b-1|+|c-1|\}}{3} \times 100 \%=$

$\frac{\{|1,04-1|+|0,53-1|+|1,41-1|\}}{3} \times 100 \%=30 \%$

4.3. Analisa losses karena adanya arus netral trafo 4.3.1. Siang hari

Arus netral yang terjadi menyebabkan losses sebagai berikut :

$$
\begin{aligned}
P_{N} & =I_{N^{2}} \times R_{N}=110^{2} \times 0,6842\left(50 \mathrm{~mm}^{2}\right) \\
& =8278,82 \mathrm{Watt} \approx 8,27 \mathrm{~kW}
\end{aligned}
$$

Penghantar netral Jika menggunakan ukuran penghantar fasa $\left(70 \mathrm{~mm}^{2}\right)$

$$
\begin{aligned}
P_{N}=I_{N^{2}} \times R_{N} & =110^{2} \times 0,5049\left(70 \mathrm{~mm}^{2}\right) \\
& =6109,29 \text { Watt } \approx 6,10 \mathrm{~kW}
\end{aligned}
$$

Daya aktif pada Trafo $P=S . \operatorname{Cos} \emptyset$

$\operatorname{Cos} \emptyset=0,8$. Didapat $P=128 \mathrm{~kW}$

Sehingga persentase losses yang timbul dengan terjadinya arus netral adalah:

$\% P_{N}=\frac{P_{N}}{P} \times 100 \%=\frac{8,27 \mathrm{KW}}{128 \mathrm{KW}} \times 100 \%=6,4 \%$

Penghantar netral Jika menggunakan ukuran penghantar fasa $50 \mathrm{~mm}^{2}$

$\% P_{N}=\frac{P_{N}}{P} \times 100 \%=\frac{6.10 \mathrm{KW}}{128 \mathrm{KW}} \times 100 \%=4.77 \%$

Losses dengan adanya arus netral yang mengalir ke tanah yaitu :

$$
\begin{aligned}
P_{G} & =I_{G^{2}} \times R_{G}=A=(60,7)^{2} \times 4 \\
& =14,737 \mathrm{~kW}
\end{aligned}
$$

Atau dalam persen :

$$
\begin{aligned}
\% P_{G} & =\frac{P_{G}}{P} \times 100 \%=\frac{14,737 \mathrm{KW}}{128 \mathrm{KW}} \times 100 \% \\
& =11,51 \%
\end{aligned}
$$




\subsubsection{Malam hari}

Kondisi pembebanan malam sebagai berikut :

$P_{N}=I_{N^{2}} \times R_{N}=111^{2} \times 0,6842\left(50 \mathrm{~mm}^{2}\right)$

$$
=8430,0282 \mathrm{Watt} \approx 8,43 \mathrm{~kW}
$$

Penghantar netral Jika menggunakan penghantar fasa $\left(70 \mathrm{~mm}^{2}\right)$

$$
\begin{array}{r}
P_{N}=I_{N^{2}} \times R_{N}=111^{2} \times 0,5049\left(70 \mathrm{~mm}^{2}\right) \\
=6220,87 \text { Watt } \approx 6,22 \mathrm{~kW}
\end{array}
$$

Persentase losses-nya karena arus netral pada penghantar trafo :

$\% P_{N}=\frac{P_{N}}{P} \times 100 \%=\frac{8,43 K W}{128 K W} \times 100 \%=6,58 \%$

$50 \mathrm{~mm}^{2}$ )

$\% P_{N}=\frac{P_{N}}{P} \times 100 \%=\frac{6,22 K W}{128 K W} \times 100 \%=4,85 \%$ $70 \mathrm{~mm}^{2}$ ) adalah :

Losses akibat arus netral yang mengalir ke tanah

$P_{G}=I_{G^{2}} \times R_{G}=A=(55,6)^{2} \times 4=12,36 \mathrm{~kW}$

Dengan Persentase :

$\% P_{G}=\frac{P_{G}}{P} \times 100 \%=\frac{12,36 K W}{128 K W} \times 100 \%=9,65 \%$

Tabel 3. Losses pada trafo distribusi 160kVA

\begin{tabular}{|c|c|c|c|c|c|c|c|c|}
\hline RN & Waktu & $\begin{array}{l}\text { Ketidaksembangan } \\
\text { beban }(\%)\end{array}$ & $\begin{array}{c}I_{N} \\
(\mathrm{~A})\end{array}$ & $\begin{array}{c}P_{N} \\
(\mathrm{~A})\end{array}$ & $\begin{array}{c}P_{N} \\
(\mathrm{~kW})\end{array}$ & $\begin{array}{c}P_{G} \\
(\%)\end{array}$ & $\begin{array}{c}P_{G} \\
(\mathrm{~kW})\end{array}$ & $(\%)$ \\
\hline $\begin{array}{l}0,0842 \\
\left(50 \mathrm{~mm}^{2}\right)\end{array}$ & Siang & 41 & 110 & 60,7 & 8,27 & 6,4 & 14,737 & 11,51 \\
\cline { 2 - 9 } & Malam & 30 & 111 & 55,6 & 8,43 & 6,58 & 12,36 & 9,65 \\
\hline $\begin{array}{l}0,5049 \\
\left(70 \mathrm{~mm}^{2}\right.\end{array}$ & Siang & 41 & 110 & 60.7 & 6.10 & 4,77 & 14,737 & 11,51 \\
\cline { 2 - 9 } & Malam & 30 & 111 & 55.6 & 6.22 & 4.85 & 12,36 & 9,65 \\
\hline
\end{tabular}

Dari tabel 2 dapat dibuat grafik nilai arus dan Losses seperti yang ditunjukkan gambar 4 dan 5 berikut,

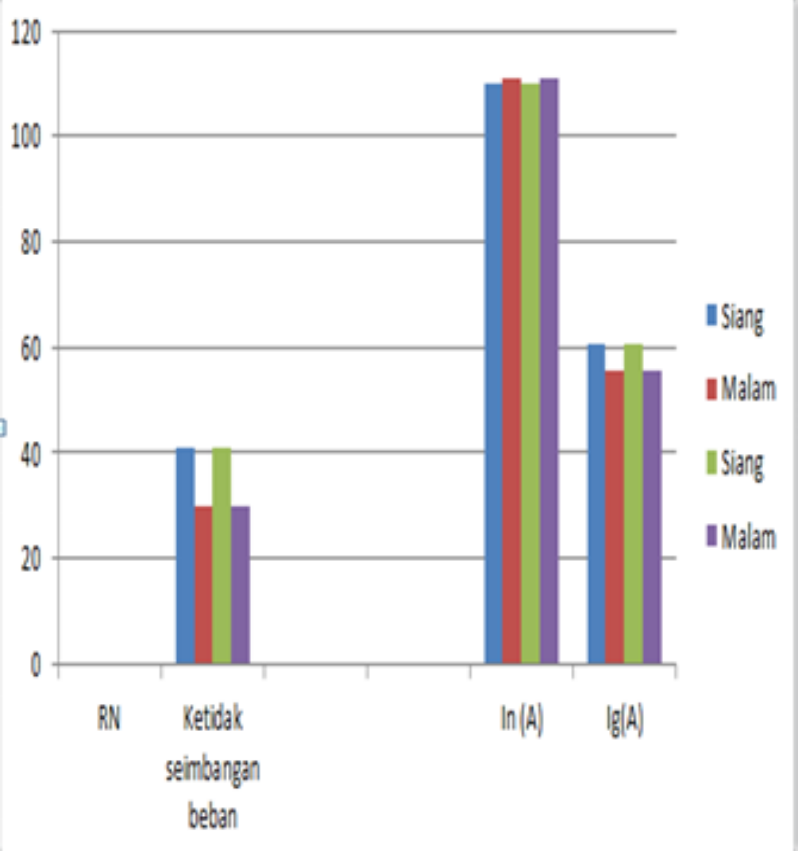

Gambar 4. Grafik Arus

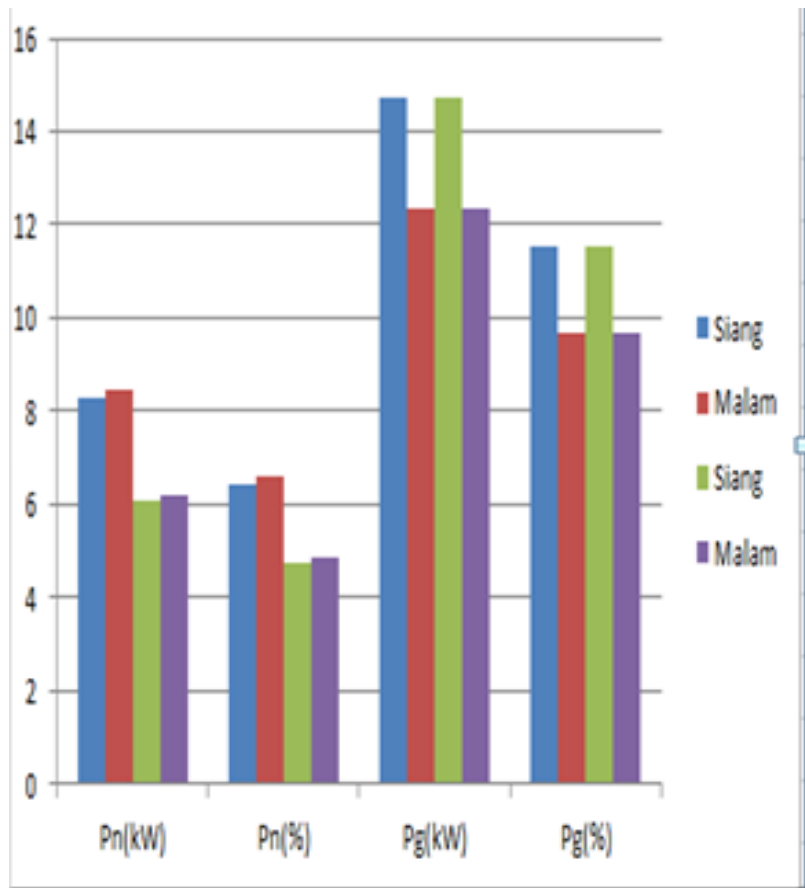

Gambar 5. Grafik Losses

Pada tabel dan grafik losses trafo distribusi 160kVA dapat kita lihat bahwa, semakin besar arus netral yang mengalir di penghantar trafo maka losses yang terjadi di arus netral juga semakin besar.

IN arus netral pada trafo sebesar $111 \mathrm{~A}$ dengan persentase losses sebesar 6,58\% pada malam hari.

Begitu pula arus yang mengalir ke tanah, semakin besar arus netral yang menagalir ketanah pada trafo maka losses pada penghantar tanah juga semakin besar.

IG arus netral yang mengalir ke tanah 60,7A dengan persentase losses $11,51 \%$ pada siang hari

\subsection{Analisa Efisiensi}

Pada Siang hari 


$$
\begin{aligned}
& \eta=\frac{\text { Pout }}{\text { Pin }} x 100 \% \\
& \text { Pout }=(a+b+c) \cdot \text { V.I.Cos } \emptyset \\
& =(0,94+0,43+1,61) 400.123,7 \cdot 0,8 \\
& =117960 \mathrm{~W}=117,96 \mathrm{~kW} \\
& \text { Pin } \quad=\text { Pout }+ \text { Rugi Rugi } \\
& =117,96+8,27 \\
& =126,23 \mathrm{~kW} \\
& \eta=\frac{117,96 \mathrm{~kW}}{126,23 \mathrm{~kW}} \quad \mathrm{x} 100 \%=93,44 \% \\
& \eta=\frac{\text { Pout }}{\text { Pin }} \quad x 100 \% \\
& \text { Pout }=(a+b+c) \cdot V \cdot I \cdot \operatorname{Cos} \emptyset \\
& =(1,04+0,53+1,41) \cdot 400 \cdot 163,7 \cdot 0,8 \\
& =156104 \mathrm{~W}=156,104 \mathrm{~kW} \\
& \text { Pin = Pout }+ \text { Rugi Rugi } \\
& =156,104+8,43 \\
& =164,534 \mathrm{~kW}
\end{aligned}
$$

Dari Perhitungan di atas dapat diperoleh efesiensi dan efesiensi terbesar terjadi pada malam hari itupun beda $1 \%$ yang terjadi pada siang hari.

\section{KESIMPULAN}

Dari tabel dan grafik dapat diketahui jika kawat netral berukuran $\left(50 \mathrm{~mm}^{2}\right)$ maka arus yang melewati kabel netral dengan persentasi 6,4\% untuk siang hari dan untuk ukuran kabel $\left(70 \mathrm{~mm}^{2}\right.$ ) maka dapat mengurangi daya yang mengalir ke netral dengan persentase sebesar 4,77\% untuk pembebanan siang.

Prosentase (\%) Efesiensi yang terjadi lebih besar pada pembebanan malam yaitu $94.87 \%$ sedangkan untuk siang hari sebesar 93,44\% yang berada di J1. Hos Cokrominoto Wisma Ombilin.

\section{DAFTAR PUSTAKA}

[1] Abdul Kadir (1981), "Electric Transformer", Pradnya Paramita Jakarta

[2] Aditya, L. (2017). Jurnal Ilmiah Elektrokrisna Vol. 6 No.1 Oktober 2017. 6(1), 33-41.

[3] Ginting, Y., Tamba, P., \& Agung, U. D. (2019). Sistem Pentanahan Pada Jaringan Distribusi Di PT. PLN

( Persero ). VIII(September), 81-86.

[4] Ohoiwutun, J., Dwiyanto, M., \& Sogen, T. (2019). Analisis Pengaruh Ketidakseimbangan Beban Terhadap Efisiensi Transformator Distriusi 100 kVA pada PT. PLN (PERSERO).

[5] Sentosa Setiadji, J., Machmudsyah, T., \& Isnanto, Y. (2008). Pengaruh Ketidakseimbangan Beban Terhadap Arus Netral dan Losses pada Trafo Distribusi. Jurnal Teknik Elektro, 7(2), 68-73. https://doi.org/10.9744/jte.7.2.68-73
[6] Stevenson, William D. 2000. Analisa Sistem Tenaga Listrik. Diterjemahkan Oleh: Kamal Idris. Jakarta

[7] Tobi, M. D. (2018). Analisis Pengaruh Ketidakseimbangan Beban Terhadap Arus Netral Dan Losses Pada Transformator Distribusi Di PT PIN (Persero) Area Sorong.

\section{Biodata Penulis}

Arfita Yuana Dewi, Lahir di Padang, 24 Januari 1975, Menyelesaikan Pendidikan Sarjana Teknik Elektro di Sekolah Tinggi Teknik Padang, dan Magister Teknik di Universitas Gadjah Mada Yogyakarta bidang Sistem Tenaga Listrik Jurusan Teknik Elektro .

Asnal Effendi, Lahir di Jakarta, 19 Juni 1973, Menyelesaikan Pendidikan Sarjana Teknik Elektro di Sekolah Tinggi Teknik Padang, dan Magister Teknik di Universitas Gadjah Mada Yogyakarta, bidang Sistem Tenaga Listrik Jurusan Teknik Elektro.

Fahody M. Syafar, Menyelesaikan pendidikan Sarjana Teknik Elektro di Institut Teknologi Padang Jurusan Teknik Elektro pada tahun 2020. 